Letters

\section{The \#ASRASpring20 conference was canceled due to COVID-19 but the science survives and thrives}

\section{To the Editor}

The 2020 American Society of Regional Anesthesia and Pain Medicine (ASRA) annual regional anesthesiology meeting was an unfortunate casualty of the COVID-19 pandemic. This meeting had to be canceled due to the 'stay home' Executive Order issued by the Governor of California on 19 March $2020^{1}$ and was not converted to a virtual format due to the short time frame and significant complexity of the meeting.

Attending scientific conferences is ingrained in our culture of medicine. We attend to refresh our knowledge, earn continuing medical education credit, network, and socialize with friends and colleagues. A key part of most modern medical conferences is showcasing the newest research in the form of abstracts or posters in both open display sessions and moderated discussions with conference faculty and attendees. In recent years, the ASRA spring meeting has typically had $>1000$ attendees with $>300$ abstract presentations. As the original meeting dates approached, the abstracts and posters were published online with a link on the ASRA website. $^{2}$

Although not a formal effort by ASRA, ASRA members and leaders active on social media began to tweet about and discuss abstracts they read. ${ }^{3}$ Based on his experience hosting recent live chats on COVID19, RKG announced a series of livestreamed poster discussions to take place during the scheduled week of the spring meeting and advertised them on Twitter using the meeting's registered hashtag \#ASRASpring20. RKG invited other ASRA expert faculty to participate in these online moderated poster sessions and used StreamYard (www.streamyard.com), a platform that accommodated guests, live commentary, and screen sharing while livestreaming the content to Twitter/ Periscope, Facebook, and YouTube simultaneously. Abstract authors were invited to present their work, and viewers could contribute questions as written comments on all three social media platforms during the livestream.

On six consecutive business days 20-27 April 2020, we livestreamed sessions for 1-1.5 hours covering preselected abstracts based on themes (acute pain, regional anesthesia, medically challenging cases, erector spinae plane block, best of meeting, and point of care ultrasound). As of 28 April 2020, 1101-2118 people accessed individual livestream sessions from all three platforms (table 1). Since \#ASRASpring20 was registered with Symplur (Pasadena, CA), free Twitter analytics were available. During the 8-day period of livestreamed sessions, there were 210 \#ASRASpring20 participants who tweeted 634 times and generated 2.13 million impressions. In comparison, there were 1.46 million impressions in $2016^{4}$ and 4.05 million impressions in $2017,{ }^{5}$ and each meeting had $>1000$ registered attendees. A poll of @ASRA_Society Twitter followers yielded 92 responses, and over 60\% agreed with the statement 'The \#ASRASpring20 Livestream poster sessions were more engaging than prior moderated poster sessions in which I have participated. ${ }^{6}$

In the post-COVID-19 era, the future of in-person medical conferences is unclear. The return to large live events and the full conversion to virtual meetings to maintain physical distancing likely represent opposite poles. Perhaps the ideal way forward will be a hybrid model that leverages the advantages of each format. One key observation from our experience with \#ASRASpring20 is that only the science survived. With the cancelation of the meeting, we lost the plenary lectures, problem-based learning discussions, workshops, interactive sessions, networking, and social events. However, the livestreamed moderated poster sessions successfully preserved and highlighted the cutting-edge science in our specialty. This format generated a global audience for the authors of the abstracts that far exceeded the experience at traditional conferences. While we do not endorse fully replacing the in-person conference experience, we recommend that future planning committees consider integrating the livestreamed poster discussion format as an element of medical conferences.

Rajnish K Gupta ๑ , ${ }^{1}$ Edward R Mariano $\odot,,^{2,3}$ Samer Narouze, ${ }^{4}$ Nabil M Elkassabany ${ }^{5}$

'Department of Anesthesiology, Vanderbilt University Medical Center, Nashville, Tennessee, USA

Table 1 Livestream viewership by session for each platform and in aggregate as of 28 April 2020

\begin{tabular}{|c|c|c|c|c|c|c|c|}
\hline Date & Title & $\begin{array}{l}\text { Twitter @ASRA_ } \\
\text { Society }\end{array}$ & $\begin{array}{l}\text { Twitter @ } \\
\text { dr_rajgupta }\end{array}$ & $\begin{array}{l}\text { Facebook } \\
@ \text { @ASRA }\end{array}$ & $\begin{array}{l}\text { YouTube } \\
\text { ASRA }\end{array}$ & $\begin{array}{l}\text { YouTube } \\
\text { ASRA RAPP }\end{array}$ & Total \\
\hline 20 April 2020 & $\begin{array}{l}\text { ABSTRACTS Day } 1 \text { - Discussing \#AcutePain Abstracts from } \\
\text { \#ASRASpring20 with @ASRA_Society. Come Join the conversation! }\end{array}$ & 420 & 1172 & 526 & 32 & 0 & 2118 \\
\hline 21 April 2020 & $\begin{array}{l}\text { ABSTRACTS Day } 2 \text { - Join @dr_rajgupta, @nelkassabany, @ } \\
\text { rljohnsonmd, \& @emarianomd as we discuss \#RegionalAnesthesia } \\
\text { Abstracts from \#ASRASpring20! LIVE at } 3 \text { pm EST on 4/20. }\end{array}$ & 338 & 608 & 602 & 14 & 2 & 1548 \\
\hline 22 April 2020 & $\begin{array}{l}\text { ABSTRACTS Day } 3 \text { - Talking about some of the Medically } \\
\text { Challenging Case Abstracts from \#ASRASpring20. @ASRA_Society } \\
\text { @ESRA_Society @dr_rajgupta @nelkassabany @jattarab }\end{array}$ & 332 & 402 & 1300 & 6 & 1 & 2034 \\
\hline 23 April 2020 & $\begin{array}{l}\text { ABSTRACTS Day } 4 \text { - We're talking about ESP blocks LIVE! Come join } \\
\text { @ASRA_Society for \#ASRASpring20 abstracts! @dr_rajgupta @ } \\
\text { nelkassabany @KiJinnChin @Ropivacaine }\end{array}$ & 447 & 651 & 354 & 12 & 1 & 1452 \\
\hline 24 April 2020 & $\begin{array}{l}\text { ABSTRACTS Day } 5 \text { - Join our amazing @ASRA_Society Faculty as } \\
\text { we discuss the Best of Meeting Abstracts from \#ASRASpring20. @ } \\
\text { dr_rajgupta @NarouzeMD @SLKoppMD @megrosenblatt }\end{array}$ & 254 & 546 & 301 & 9 & 2 & 1101 \\
\hline 27 April 2020 & $\begin{array}{l}\text { ABSTRACTS Day } 6 \text { - We're LIVE now! Discussing \#POCUS } \\
\text { abstracts from the @ASRA_Society \#ASRASpring20 Meeting. } \\
\text { Share! @KalagaraHari @shaskinsMD @JanBoublikMDPhD @ } \\
\text { dr_melissabyrne }\end{array}$ & 427 & 725 & 661 & 38 & 41 & 1813 \\
\hline
\end{tabular}

Videos are enduring content online; therefore, viewership numbers can increase over time.

ASRA, American Society of Regional Anesthesia and Pain Medicine; RAPP, Regional Anesthesia and Pain Podcast. 
${ }^{2}$ Anesthesiology and Perioperative Care Service, Veterans Affairs Palo Alto Health Care System, Palo Alto, California, USA

${ }^{3}$ Department of Anesthesiology, Perioperative and Pain Medicine, Stanford University School of Medicine, Stanford, California, USA

${ }^{4}$ Center for Pain Medicine, Summa Western Reserve Hospital, Cuyahoga Falls, Ohio, USA

${ }^{5}$ Department of Anesthesiology and Critical Care, University of Pennsylvania, Philadelphia, Pennsylvania, USA

Correspondence to Dr Edward R Mariano, Anesthesiology and Perioperative Care Service, VA Palo Alto Health Care System, Palo Alto, CA 37232, USA; emariano@stanford.edu

Twitter Rajnish K Gupta @dr_rajgupta, Edward R Mariano @EMARIANOMD and Samer Narouze @ NarouzeMD

Contributors RKG helped design the project, collected data, drafted and revised the initial manuscript, reviewed and approved the submitted manuscript. ERM helped design the project, drafted and revised the initial manuscript, reviewed and approved the submitted manuscript. SN reviewed the data, revised the initial manuscript, reviewed and approved the submitted manuscript. NME helped design the study, revised the initial manuscript, reviewed and approved the submitted manuscript.

Funding ERM's contribution to this material was supported with resources and the use of facilities at the Veterans Affairs Palo Alto Health Care System (Palo Alto, (A, USA).

Competing interests None declared.

Patient consent for publication Not required.

Provenance and peer review Not commissioned; internally peer reviewed.

This article is made freely available for use in accordance with BMJ's website terms and conditions for the duration of the covid-19 pandemic or until otherwise determined by BMJ. You may use, download and print the article for any lawful, non-commercial purpose (including text and data mining) provided that all copyright notices and trade marks are retained.

(C) American Society of Regional Anesthesia \& Pain Medicine 2021. No commercial re-use. See rights and permissions. Published by BMJ.

\section{A Check for updates}

To cite Gupta RK, Mariano ER, Narouze S, et al. Reg Anesth Pain Med 2021;46:374-375.

Received 29 April 2020

Accepted 30 April 2020

Published Online First 13 May 2020

Reg Anesth Pain Med 2021;46:374-375.

doi:10.1136/rapm-2020-101645

ORCID iDs

Rajnish K Gupta http://orcid.org/0000-0003-3401-

4737

Edward R Mariano http://orcid.org/0000-0003-2735$248 X$

\section{REFERENCES}

1 Executive Department State of California. Executive order N-33-20. Available: https://covid19.ca.gov/img/ExecutiveOrder-N-33-20.pdf [Accessed 29 Apr 2020].

2 45th annual regional anesthesiology and acute pain medicine meeting 2020. Available: https://epostersonline. com/ASRASPRING20/ [Accessed 29 Apr 2020].
3 Narouze S. Available: https://twitter.com/NarouzeMD/status/ 1251347661971734535 [Accessed 29 Apr 2020].

4 Schwenk ES, Jaremko KM, Gupta RK, et al. Upgrading a social media strategy to increase Twitter engagement during the spring annual meeting of the American Society of regional anesthesia and pain medicine. Reg Anesth Pain Med 2017;42:283-8.

5 Schwenk ES, Jaremko KM, Park BH, et al. I Tweet, therefore I learn: an analysis of Twitter use across anesthesiology conferences. Anesth Analg 2020;130:333-40.

6 ASRA_Society. Available: https://twitter.com/ASRA_ Society/status/1255222652576374796 [Accessed 29 Apr 2020]. 